\title{
Evaluation of the New Compound Oxathiapiprolin for Control of Downy Mildew in Basil
}

\begin{abstract}
Jaimin S. Patel, Tropical Research and Education Center, Department of Plant Pathology, University of Florida/IFAS, Homestead 33031; Maria I. Costa de Novaes, Tropical Research and Education Center, Department of Plant Pathology, University of Florida/IFAS, Homestead 33031 (sponsored by CNPq, current address: Departamento de Ciências Agrárias, Unimontes, Campus de Janauba, Caixa postal 91, Rua Reinaldo Viana, 2630, CEP 39440-000, Janauba-MG, Brazil); and Shouan Zhang, Tropical Research and Education Center, Department of Plant Pathology, University of Florida/IFAS, Homestead 33031
\end{abstract}

Accepted for publication 1 November 2015. Published 13 November 2015.

\section{ABSTRACT}

Patel, J. S., Costa de Novaes, M. I., and Zhang, S. 2015. Evaluation of the new compound oxathiapiprolin for control of downy mildew in basil. Plant Health Progress doi:10.1094/PHP-RS-15-0026.

This study was conducted to evaluate a new chemical, oxathiapiprolin, as a seed treatment and foliar application for control of downy mildew of basil, caused by Peronospora belbahrii, and to assess the in vitro sensitivity of $P$. belbahrii to oxathiapiprolin. In the greenhouse, both foliar application and seed treatment with oxathiapiprolin significantly $(P<0.05)$ reduced downy mildew severity on basil and increased width of cotyledons compared to the non-treated control. In field experiments, foliar applications of oxathiapiprolin alone, as a tank mixture, or in alternation with azoxystrobin, potassium phosphite, or tea tree oil significantly reduced downy mildew severity and increased the basil yield compared to the non-treated control. In the laboratory test, $\mathrm{EC}_{50}$ values of sensitive $P$. belbahrii isolates ranged from $0.00033 \mu \mathrm{g} / \mathrm{ml}$ to 0.00040 $\mu \mathrm{g} / \mathrm{ml}$ oxathiapiprolin, providing important information on baseline sensitivity of $P$. belbahrii to oxathiapiprolin. The results indicate that oxathiapiprolin can be applied as foliar applications in combination or in alternation with azoxystrobin or potassium phosphite to control the disease effectively.

\section{INTRODUCTION}

Sweet basil (Ocimmum basilicum L.) is the most commonly commercially grown and economically important species of basil in the world. Basil plants accumulate a wide variety of terpenes and phenylpropanoids, which are constituents of the plants' aromatic volatile oils, also known as essential oils (Gang et al. 2001; Vieira and Simon 2000; Vieira et al. 2001). Field and greenhouse production of fresh basil has significantly increased in recent years due to the increasing demand of the fragrance, flavor, fresh culinary, and dried herb industries and the high cash value of basil (Simon et al. 1990, 1999; Wyenandt et al. 2015).

Downy mildew of basil, caused by the oomycete Peronospora belbahrii Thines, has been detected from all basil-growing continents, and is becoming a global threat to basil production (Garibaldi et al. 2004a; Garibaldi et al. 2005; Khateri et al. 2007; McLeod et al. 2006; Ronco et al. 2009; Roberts et al. 2009). In the United States, downy mildew was first detected in basil from Homestead, FL, in 2007 (Roberts et al. 2009). Since then, the pathogen has spread rapidly, and has been reported in 42 states and the District of Columbia, according to a monitoring program during 2009-2014 (Wyenandt et al. 2015). Downy mildew has become the most devastating foliar disease in basil and is now a major limiting factor for basil production in the United States. Downy mildew of basil develops and spreads rapidly during periods of high humidity, mild temperatures, and prolonged durations of leaf wetness. Basil infected with $P$. belbahrii is not

Corresponding author: Shouan Zhang. Email: szhang0007@ufl.edu.

doi:10.1094/PHP-RS-15-0026

(C) 2015 The American Phytopathological Society marketable and this disease can cause significant loss of the crop (Wyenandt et al. 2010). Strategies for management of basil downy mildew are very limited owing to the fact that the disease was found so recently, the lack of host resistance in commercially grown sweet basil, and the scarcity of choices of effective fungicides currently registered on basil.

Fungicides with multi-site effects, including dithiocarbamates (e.g., mancozeb), chloronitriles (chlorothalonil), and copper formulations, are commonly used for control of downy mildew diseases. However, only a few fungicides are currently registered to use on basil for downy mildew control, including azoxystrobin (Quadris), potassium phosphite (Prophyt), mandipropamid (Revus), and cyzofamide (Ranman). Therefore, evaluating new fungicides that belong to novel chemical classes is imperative to maintain the effectiveness of fungicides currently registered for management of downy mildew of basil through tank mixing and alternating them with different classes of fungicides. Oxathiapiprolin (Orondis) is the first of the new piperidinyl thiazole isoxazoline class of fungicides discovered and developed by DuPont Co. (Wilmington, DE). Oxathiapiprolin (molecular formula: $\mathrm{C}_{24} \mathrm{H}_{22} \mathrm{~F}_{5} \mathrm{~N}_{5} \mathrm{O}_{2} \mathrm{~S}$ ) represents a novel chemical compound that offers growers new options for control of plant diseases caused by the oomycete pathogens (Shepherd et al. 2013). The objectives of this study were to evaluate oxathiapiprolin applied as a seed treatment and foliar applications for its efficacy to control downy mildew of basil under greenhouse and field conditions, and to determine the effectiveness of oxathiapiprolin when it was applied as tank mixes or in alternation with other registered fungicides of different chemical classes. In addition, in vitro assays were conducted to assess sensitivity of $P$. belbahrii to oxathiapiprolin. 


\section{EVALUATION OF OXATHIAPIPROLIN FOR MANAGEMENT OF DOWNY MILDEW OF BASIL UNDER GREENHOUSE CONDITIONS}

Seeds of sweet basil cultivar Genovese purchased from Eden Brothers (Dohlonega, GA) were used in all experiments. Four to five seeds were planted in 10-cm-diameter plastic pots containing Fafard \#2 mix (Fafard Inc., Agawam, MA) supplemented with a slow-releasing fertilizer (Scotts Company, Marysville, $\mathrm{OH}$ ) as needed. High humidity in the greenhouse was maintained at 80 to $95 \%$ by activating the overhead irrigation system equipped with 360 NN-GR Nifty nozzles (Dramm Corporation, Manitowoc, WI) four times a day for five minutes.

In experiment 1 , basil plants were grown in a greenhouse where the pathogen $P$. belbahrii was maintained on basil plants for research purposes and the pathogen was present in abundance for natural infection. The objective was to evaluate seed treatment at various rates under pressure of pathogen attacks on basil seedlings starting from planting (seeding). Oxathiapiprolin was tested as a seed treatment at the rates of 0.005, 0.009, 0.018, $0.037,0.073$, and 0.146 liter/ha (Table 1). Basil seeds were added to solutions of oxathiapiprolin and mixed well with a magnetic stir bar on a magnetic stirrer for approximately $40 \mathrm{~min}$. After the solution was drained, basil seeds were air dried for 4 to $6 \mathrm{~h}$ prior to planting. A non-treated control (water) and a chemical standard, azoxystrobin (Quadris; Syngenta, Greensboro, NC), as foliar sprays, were included. The first foliar spray of azoxystrobin at the registered rate of 0.658 liter/ha was applied when two cotyledons of each plant fully developed, i.e., 6 days after planting (DAP).

The objective of experiment 2 was to evaluate seed treatment and foliar sprays of the chemicals as preventive control measures on basil seedlings. In experiment 2, basil plants were grown in a separate pathogen-free greenhouse. Oxathiapiprolin was evaluated as a seed treatment at the same rates as described in experiment 1 and also as foliar sprays at 0.018,0.037, 0.073, and 0.146 liter/ha at a 7 -day spray interval (Table 2). A non-treated control (water) and a chemical standard (azoxystrobin as foliar sprays) were included also in this experiment. The first foliar application of azoxystrobin and oxathiapiprolin was made when the first true leaves fully expanded, i.e., 16 DAP. All treatments were arranged in a randomized complete block design with five and six replications for each treatment in experiment 1 and 2 , respectively. One pot was considered as one replication and each pot contained 4 to 5 basil plants. One day after foliar application of the chemicals, basil plants were inoculated with $P$. belbahrii at $1 \times 10^{3}$ sporangia/ml by spraying the sporangial suspension onto the leaves until runoff. The inoculum of $P$. belbahrii was prepared by washing off fresh sporangia into sterile water from the underside of basil leaves. Inoculated plants were maintained in a humidity chamber (built in a greenhouse) for $24 \mathrm{~h}$ before they were moved to benches in the same greenhouse. Temperature in the greenhouse equipped with an air conditioner was set to $22^{\circ} \mathrm{C}$;

\begin{tabular}{|c|c|c|c|c|}
\hline Treatment & $\begin{array}{c}\text { Rate } \\
\text { (liter/ha) }\end{array}$ & Application method & $\begin{array}{c}\text { Disease severity (\%) } \\
26 \text { DAPX }\end{array}$ & AUDPC \\
\hline Azoxystrobin & 0.658 & Foliar spray & $52.0 \mathrm{c}$ & $393.5 \mathrm{~d}$ \\
\hline Azoxystrobin & 0.658 & Seed treatment & $65.0 \mathrm{~b}$ & $523.0 \mathrm{~b}$ \\
\hline Azoxystrobin & 1.315 & Seed treatment & $64.0 \mathrm{~b}$ & $449.0 \mathrm{c}$ \\
\hline Oxathiapiprolin & 0.009 & Seed treatment & $28.0 \mathrm{~d}$ & $150.0 \mathrm{e}$ \\
\hline Oxathiapiprolin & 0.018 & Seed treatment & $25.0 \mathrm{de}$ & $124.5 \mathrm{ef}$ \\
\hline Oxathiapiprolin & 0.037 & Seed treatment & $20.0 \mathrm{e}$ & $77.0 \mathrm{fg}$ \\
\hline Oxathiapiprolin & 0.073 & Seed treatment & $12.6 \mathrm{f}$ & $38.5 \mathrm{gh}$ \\
\hline Oxathiapiprolin & 0.146 & Seed treatment & $8.0 \mathrm{f}$ & $25.0 \mathrm{~h}$ \\
\hline LSD & - & - & 7.18 & 51.1 \\
\hline
\end{tabular}

${ }^{\mathrm{x}}$ Data are means of five replications. Means in a column followed by the same letters are not significantly $(P=0.05)$ different.

\section{TABLE 2}

Efficacy of oxathiapiprolin for control of downy mildew of basil under greenhouse conditions in experiment 2.

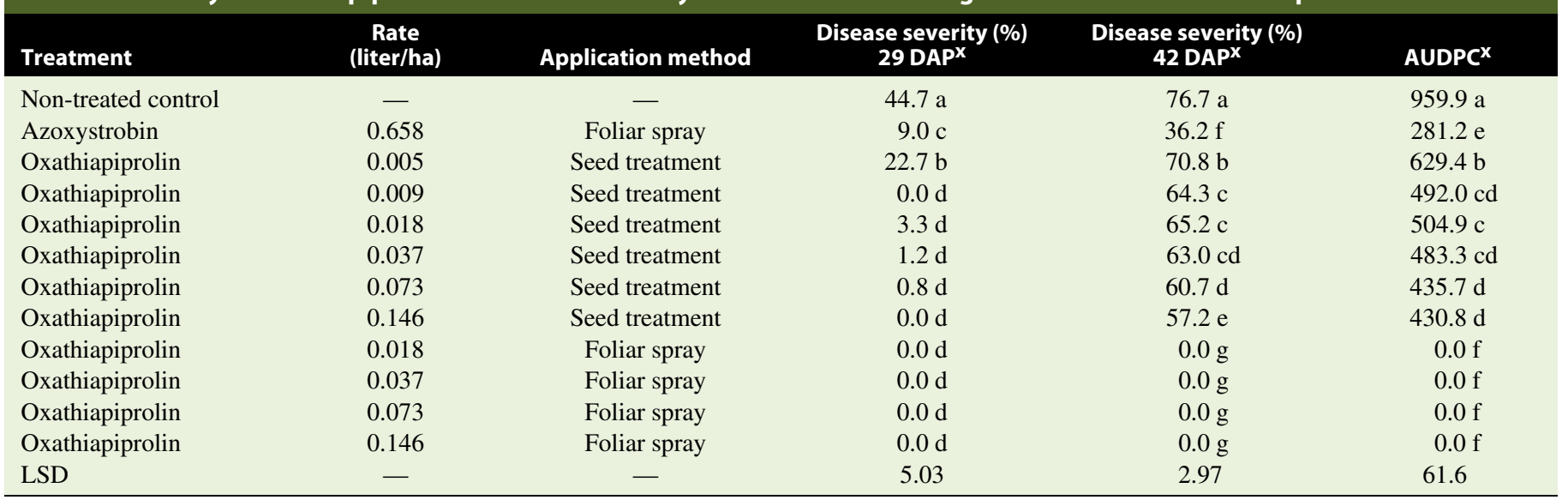

\footnotetext{
${ }^{\mathrm{x}}$ Data are means of six replications. Means in a column followed by the same letters are not significantly $(P=0.05)$ different.
} 
however, temperatures fluctuated $\pm 5^{\circ} \mathrm{C}$ each day depending on the ambient solar radiation.

Disease severity of basil downy mildew was visually assessed as the percentage of symptomatic leaf area (sign and symptoms) 14, 16, 21, and 26 DAP in experiment 1, and 25, 26, 29, 32, 35, and 42 DAP in experiment 2 . Single disease severity reading was recorded for each replication consisting of 4 to 5 plants. The area under the disease progress curve (AUDPC) was calculated based on the four and six ratings in experiment 1 and 2, respectively (Shaner and Finney 1977). To determine the plant response to oxathiapiprolin treatment, the length and width of cotyledons were measured 28 and 33 DAP in experiment 1 and 2, respectively. Data of downy mildew disease, and the length and width of cotyledons were subjected to analysis of variance (ANOVA). Statistical analyses were conducted using SAS 9.3 software (SAS Institute Inc., Cary, NC). The treatment means were separated by Fisher's protected least significant difference (LSD) at $P=0.05$.

\section{ASSESSMENT OF OXATHIAPIPROLIN FOR MANAGEMENT OF DOWNY MILDEW OF BASIL UNDER FIELD CONDITIONS}

Seeds of sweet basil 'Genovese' were planted into fumigated beds (106 m long, $91 \mathrm{~cm}$ wide, and $15 \mathrm{~cm}$ high) covered with plastic mulch on 16 May 2013 and 18 October 2013, respectively, for field experiment 1 and 2 at the University of Florida's Tropical Research and Education Center, Homestead, FL. The beds were fumigated with methyl bromide (MC 33) at $393 \mathrm{~kg} / \mathrm{ha}$ prior to being covered with plastic mulch. The treatments in these experiments were arranged in a randomized complete block design with four replications. In each plot of $292.61 \mathrm{~cm}$, seven holes $40 \mathrm{~cm}$ apart were dug using a 10-cm-diameter circular puncher, and a buffer zone of $76.2 \mathrm{~cm}$ was set between two adjacent plots. Approximately 10 seeds were placed in each hole and covered with a 4-mm-deep layer of soil. Two to three weeks after emergence, the basil in each hole was thinned to 4 to 6 seedlings. Irrigation and fertigation were provided as per optimal requirements for basil production in Florida by two drip-irrigation tapes passing by both sides of each hole.

In field experiment 1, oxathiapiprolin was evaluated as a seed treatment and as foliar sprays at 0.005, 0.009, 0.018, 0.037, 0.073, and 0.146 liter/ha (Table 3 ). The basil seeds were treated with oxathiapiprolin as described previously. The first foliar application of oxathiapiprolin was made 29 DAP and four sequential applications were made on 7-day intervals. Based on the results of experiment 1 , a single dose of 0.037 liter/ha of oxathiapiprolin was selected to apply in field experiment 2 . The aim of experiment 2 was to determine the effect of oxathiapiprolin incorporated with registered compounds for the development of integrated management strategies. Two of the organic oil products (sesame oil + fish oil, and tea tree oil) were included in experiment 2 in consideration of their reported effective performance in control of downy mildew of basil under greenhouse conditions (Patel et al. 2013). Treatments consisted of: solo applications of oxathiapiprolin at 7- and 14-day intervals; tank mix of oxathiapiprolin with azoxystrobin at 7- and 14-day intervals; tank mix of oxathiapiprolin with potassium phosphite (Prophyt, Helena, Collierville, TN) at 7-day intervals; alternation of oxathiapiprolin with azoxystrobin and potassium phosphite at 7-day intervals; seed treatment of oxathiapiprolin followed by foliar sprays of oxathiapiprolin at 0.037 liter/ha; tea tree oil (Timerox Gold, Stockton Group, Aventura, FL) (1.25\% v/v) alone; alternation of oxathiapiprolin with tea tree oil; sesame oil $5 \%$ + edible fish oil 92\% (Organocide, Home Depot) alone; and alternation of oxathiapiprolin with sesame oil $5 \%$ + edible fish oil $92 \%$ (Table 4). A non-treated control and a chemical standard (azoxystrobin 0.658 liter/ha + potassium phosphite 1.89 liters/ha) were included in both field experiments. The first foliar spray was started 25 DAP in this field experiment, and basil plants were naturally infected with $P$. belbahrii in both field experiments.

Data from both field experiments were collected from plants located at the middle five holes of each plot per replication. Therefore, data were analyzed using randomized complete block design with subsampling. Disease severity was visually assessed as the percentage of symptomatic leaf area (sign and symptoms) 47, 54, 61, 68, and 75 DAP in experiment 1, and 26, 33, 40, 47, 54 , and 61 DAP in experiment 2. The AUDPC values were calculated based on five and six ratings of disease severity in experiment 1 and 2, respectively. To determine the treatment effect on basil yield, weight of healthy leaves of the basil plants was measured 76 and 62 DAP in experiment 1 and 2, respectively.

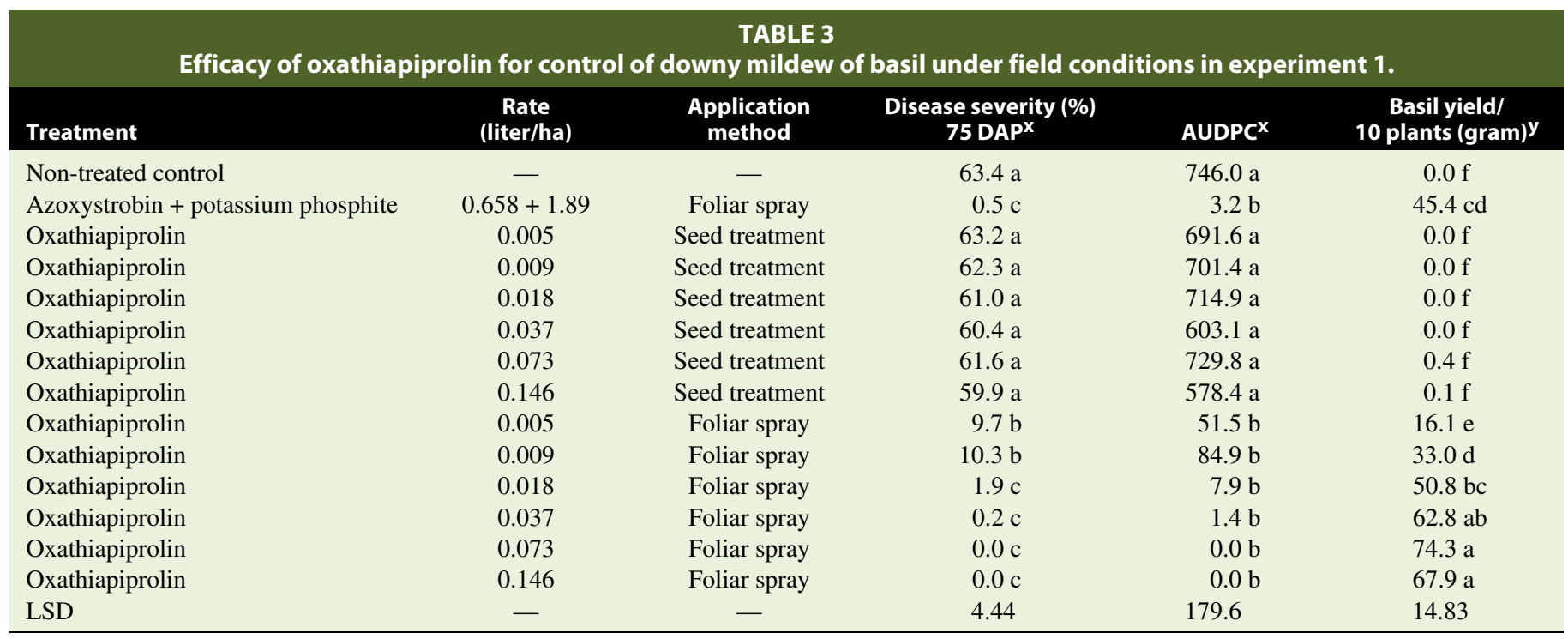

${ }^{\mathrm{x}}$ Data are means of four replications. Means in a column followed by the same letters are not significantly $(P=0.05)$ different.

y Yield was measured by weighing fresh basil leaves with no symptoms or signs of downy mildew. Means in a column followed by the same letters are not significantly $(P=0.05)$ different. 
Statistical analyses were conducted using SAS 9.3 software (SAS Institute Inc., Cary, NC). The treatment means were separated by Fisher's protected least significant difference (LSD) at $P=0.05$.

\section{LABORATORY TEST OF OXATHIAPIPROLIN FOR INHIBITING GERMINATION OF P. BELBAHRII SPORANGIA}

To determine the effect of oxathiapiprolin on germination of $P$. belbahrii sporangia, $\mathrm{EC}_{50}$ values were determined at which doses of oxathiapiprolin can inhibit 50\% germination of $P$. belbahrii sporangia. A stock solution of oxathiapiprolin $(1000 \mu \mathrm{g} / \mathrm{liter})$ was prepared by adding oxathiapiprolin $(250 \mathrm{gm}$ a.i./liter $)$ into $1 \mathrm{ml}$ water. The appropriate amount of oxathiapiprolin was added to $1.5 \%$ water agar when the temperature of media reached 45 to $50^{\circ} \mathrm{C}$ to make a final concentration of $0.0001,0.0002,0.0004$, 0.0008 , and $0.0016 \mu \mathrm{g} / \mathrm{ml}$ oxathiapiprolin. The media were then shaken well before pouring them into the Petri dishes. The nonamended water agar was also prepared. The germination rate of freshly harvested sporangia of $P$. belbahrii was evaluated by spreading $100 \mu \mathrm{l}$ sporangia suspension $\left(5 \times 10^{4}\right.$ sporangia/ml $)$ onto oxathiapiprolin-amended water agar (1.5\%) Petri dishes and the non-amended water-agar Petri dishes. The Petri dishes were sealed with Parafilm, and incubated at $10^{\circ} \mathrm{C}$ in an incubator for $8 \mathrm{~h}$. Each treatment consisted of three Petri dishes. On each plate, a total of 100 sporangia were assessed for germination using $10 \times$ objective lens under a light microscope after $8 \mathrm{~h}$ of incubation. Sporangia were considered germinated if a germ tube was visible from a sporangium under the light microscope. The experiment was repeated once and both experiments were conducted in a completely randomized design. The $\mathrm{EC}_{50}$ value of oxathiapiprolin for sporangial germination of $P$. belbahrii was determined using Proc Probit procedure in SAS 9.4 software (SAS Institute Inc., Cary, NC).

\section{EFFECT OF OXATHIAPIPROLIN ON BASIL DOWNY MILDEW IN THE GREENHOUSE}

In greenhouse experiment 1, seedlings from basil seeds treated with oxathiapiprolin at all tested rates did not show any disease symptoms until 21 DAP, whereas symptoms were first observed on non-treated plants 14 DAP. Also, symptoms were first observed on seedlings treated with azoxystrobin as a seed treatment and foliar treatment 16 DAP (data not shown). Occurrence of symptoms on basil plants from seed treatment at all tested rates of oxathiapiprolin was delayed by 7 days compared to the non-treated control. Disease severity on basil from seed treatment was significantly $(P<0.05)$ reduced 26 DAP compared to the non-treated control, azoxystrobin as a seed

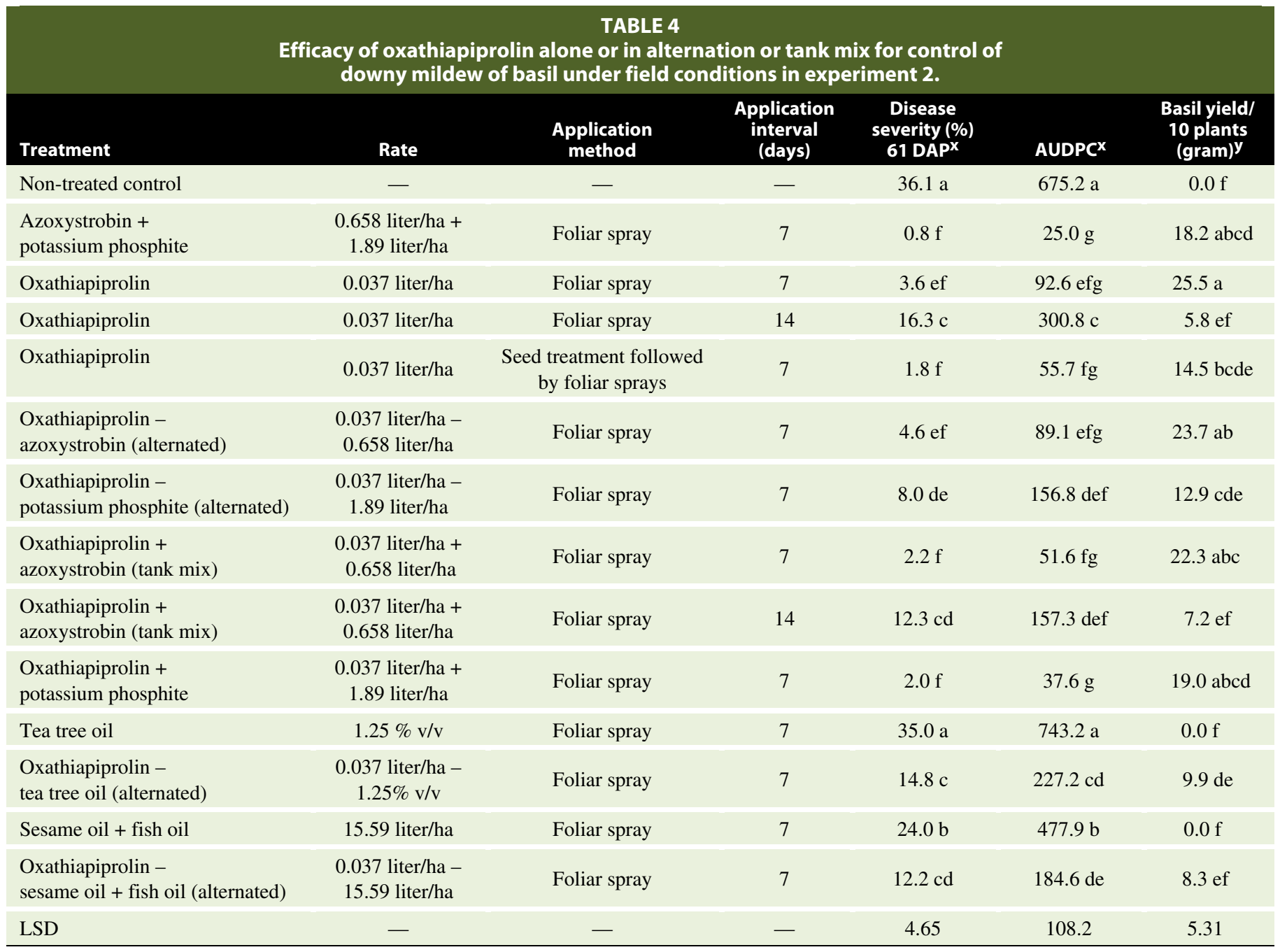

${ }^{\mathrm{x}}$ Data are means of four replications. Means in a column followed by the same letters are not significantly $(P=0.05)$ different.

y Yield was measured by weighing fresh basil leaves with no symptoms or signs of downy mildew. Means in a column followed by the same letters are not significantly $(P=0.05)$ different. 
treatment at the rate of 0.658 and 1.315 liter/ha, and azoxystrobin as foliar sprays at 0.658 liter/ha (Table 1). Basil from seeds treated with oxathiapiprolin at 0.146 liter/ha had the lowest disease severity among seed treatments (Table 1). In terms of disease development, basil plants from seed treatment with oxathiapiprolin at all tested rates resulted in a significant reduction in AUDPC compared to the non-treated control, seed treatment of azoxystrobin at 0.658 liter/ha and 1.315 liters/ha, and foliar application of azoxystrobin at 0.658 liter/ha (Table 1). Although azoxystrobin applied as a seed treatment or foliar applications significantly reduced downy mildew of basil compared to the non-treated control, foliar applications of azoxystrobin were more effective than a seed treatment.

In addition, seed treatment with oxathiapiprolin at all tested rates significantly $(P<0.05)$ increased the length and width of cotyledons of basil plants 28 DAP compared to the non-treated basil (Fig. 1A). Treatment with oxathiapiprolin at higher rates, i.e. $0.018,0.037,0.073$, and 0.146 liter/ha, also had significant effects on increase in the length and width of cotyledons compared to foliar application of azoxystrobin at 0.658 liter/ha and seed treatment with azoxystrobin at 0.658 and 1.315 liter/ha.

Azoxystrobin, a registered fungicide on basil, had little or no effect on the length or width of cotyledons.

In greenhouse experiment 2, oxathiapiprolin at six rates as seed treatment and as one foliar pre-inoculation and two postinoculation applications at four rates were applied simultaneously to assess the effect of the treatments. Basil seedlings from seeds treated with oxathiapiprolin at all tested rates had significantly lower disease severity compared to the non-treated plants until 29 DAP (Table 2). Seed treatment with oxathiapiprolin at higher rates of 0.146 and 0.073 liter/ha delayed appearance of disease symptoms by 8 and 5 days, respectively, and seed treatment at $0.037,0.018,0.009$, and 0.005 liter/ha delayed by 2 days compared to the non-treated basil. However, in this experiment 2, downy mildew disease on basil plants from seeds treated with oxathiapiprolin suddenly increased 29 DAP, and disease severity was greater on basil plants from all seed treatments 42 DAP compared to foliar sprays of azoxystrobin at 0.658 liter/ha, and oxathiapiprolin as foliar applications at the rates of $0.018,0.037$, 0.073 , and 0.146 liter/ha (Table 2). Interestingly, no symptoms developed on plants that received foliar sprays of oxathiapiprolin at tested rates of $0.018,0.037,0.073$, and 0.146 liter/ha. Basil plants treated with oxathiapiprolin as foliar applications at 0.018 , 0.037, 0.073, and 0.146 liter/ha had the lowest AUDPC values compared to all other treatments in experiment 2 (Table 2). Seed treatment with oxathiapiprolin resulted in significantly $(P<0.05)$ lower AUDPC values compared to the non-treated control, but the AUDPC was significantly $(P<0.05)$ greater than foliar applications of oxathiapiprolin at all tested rates and of azoxystrobin at 0.658 liter/ha (Table 2).

In greenhouse experiment 2, all treatments with oxathiapiprolin or azoxystrobin at tested rates, regardless of a seed treatment or foliar sprays, significantly increased the width of cotyledons compared to the non-treated control. Oxathiapiprolin as a seed treatment at 0.073 liter/ha and as foliar applications at 0.146 liter/ha significantly increased the length of cotyledons of basil plants compared to the non-treated basil (Fig. 1B).

\section{EFFECT OF OXATHIAPIPROLIN ON BASIL DOWNY MILDEW UNDER FIELD CONDITIONS}

In field experiment 1 , downy mildew was observed on basil plants in all seed treatments 54 DAP, whereas no disease was seen on basil plants that received foliar applications of oxathiapiprolin or the chemical standard (data not shown). Basil plants treated with oxathiapiprolin as foliar applications at 0.073 and 0.146 liter/ha did not exhibit any symptoms of downy mildew during the entire period of this field experiment (Table 3). In general, foliar applications of oxathiapiprolin reduced disease severity 75 DAP compared to the non-treated control and all seed treatments with oxathiapiprolin. Oxathiapiprolin applied as foliar applications at $0.018,0.037,0.073$, and 0.146 liter/ha provided levels of control of downy mildew equivalent to a tank mix of azoxystrobin with potassium phosphite; however, all seed treatments with oxathiapiprolin had no or negligible effects on reduction of downy mildew. Foliar applications of oxathiapiprolin and of a tank mix of azoxystrobin and potassium phosphite reduced the disease development as shown in AUDPC values compared to the non-treated control and all seed treatments with oxathiapiprolin (Table 3).

Symptom-free basil leaves were harvested 76 DAP to determine marketable yield of basil from each treatment. Higher yields were recorded for the basil plants treated with oxathiapiprolin as foliar applications, and the greatest yield was found from foliar treatments with oxathiapiprolin at 0.146 and 0.073 liter/ha (Table 3). All tested rates of oxathiapiprolin as a seed treatment resulted in lower yield compared to foliar applications of oxathiapiprolin and to foliar applications of a tank mix of azoxystrobin and potassium phosphite, a chemical standard in this field experiment.

In field experiment 2 , basil treated with oxathiapiprolin alone at 7- and 14-day intervals, as a tank mix with azoxystrobin and potassium phosphite at 7- and 14-day intervals, and in alternation with other tested compounds showed lower disease severity compared to the non-treated control, tea tree oil, and sesame oil 61 DAP (Table 4). Among all the treatments, oxathiapiprolin applied alone as foliar applications, a tank mix with azoxystrobin, a tank mix with potassium phosphite, and oxathiapiprolin as a seed treatment followed by foliar applications at 7-day intervals provided the best control of downy mildew on basil, equivalent to a tank mix of azoxystrobin with potassium phosphite, a chemical standard in this field experiment. Tea tree oil alone had no effect on disease reduction compared to the non-treated control. Alternating application of oxathiapiprolin with tea tree oil significantly reduced disease severity of downy mildew compared to tea tree oil alone, but not different from treatment with oxathiapiprolin at 14-day intervals. Sesame oil alone reduced downy mildew severity compared to the non-treated control. Application of oxathiapiprolin alternated with sesame oil reduced downy mildew compared to foliar applications of sesame oil alone. In terms of AUDPC values, foliar applications of oxathiapiprolin alone, oxathiapiprolin alternated with azoxystrobin, a tank mix of oxathiapiprolin and azoxystrobin, a tank mix of oxathiapiprolin and potassium phosphite each at 7day intervals, and seed treatment with oxathiapiprolin followed by weekly foliar applications significantly reduced the disease development, and the effects were equivalent to the chemical standard, a tank mix of azoxystrobin and potassium phosphite. Oxathiapiprolin applied alone as foliar sprays at 7-day intervals had lower disease severity and AUDPC value (Table 4) than foliar applications at 14-day intervals. Similarly, a tank mix of oxathiapiprolin with azoxystrobin applied at 7-day intervals resulted in significantly lower disease severity and AUDPC value (Table 4) compared to foliar applications at 14-day intervals. 
Basil treated with oxathiapiprolin alone and with a tank mix or alternation of oxathiapiprolin with azoxystrobin all applied at 7day intervals had the greatest yield among the treatments (Table 4). All treatments except tea tree oil applied at 7-day intervals, sesame oil + fish oil applied at 7-day intervals, oxathiapiprolin applied at 14-day intervals, and a tank mix of oxathiapiprolin with azoxystrobin applied at 14-day intervals increased basil yield compared to the non-treated basil. The significant reduction of

- Length $\square$ Width

A
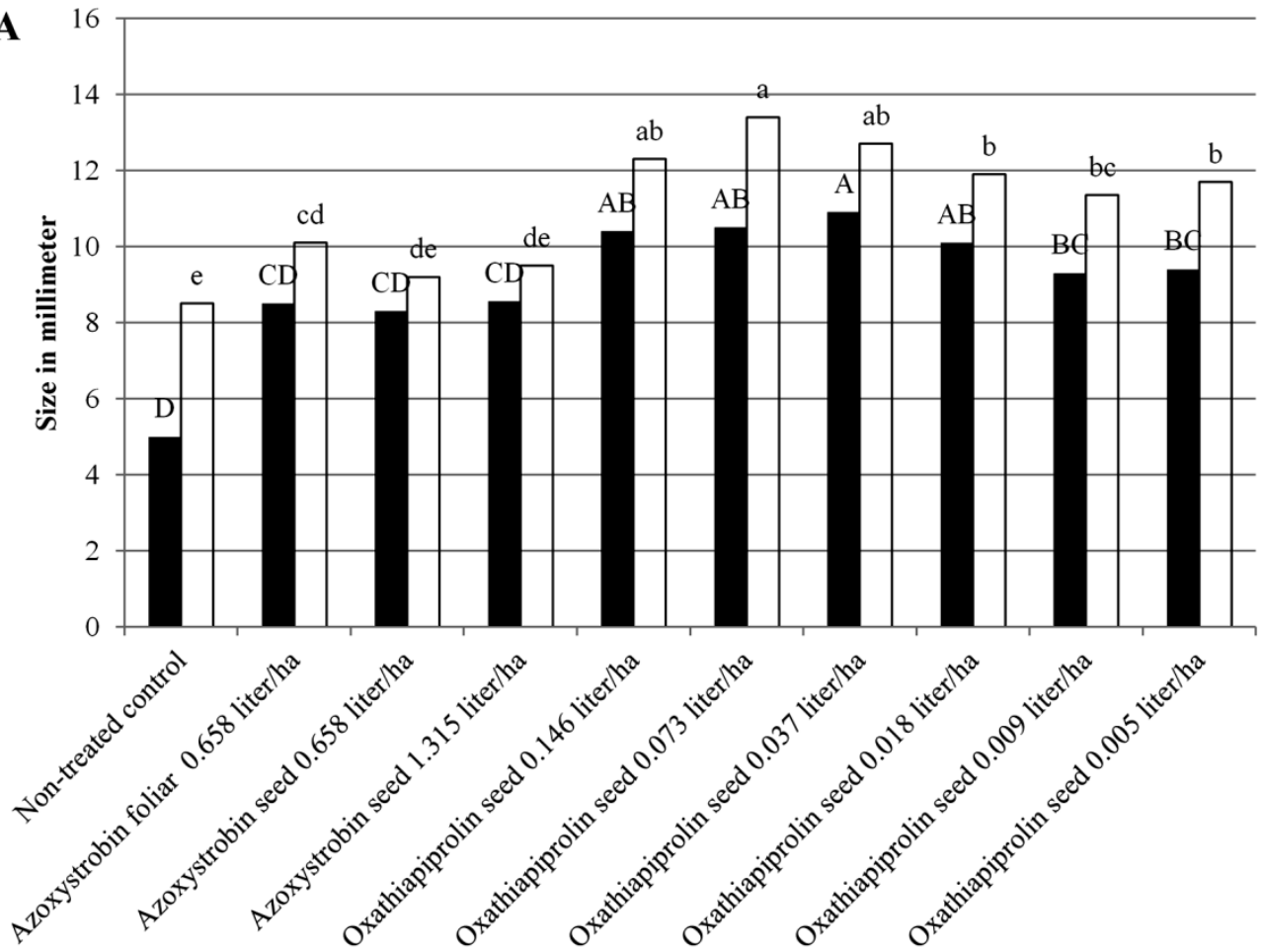

Treatments

—ength $\square$ Width
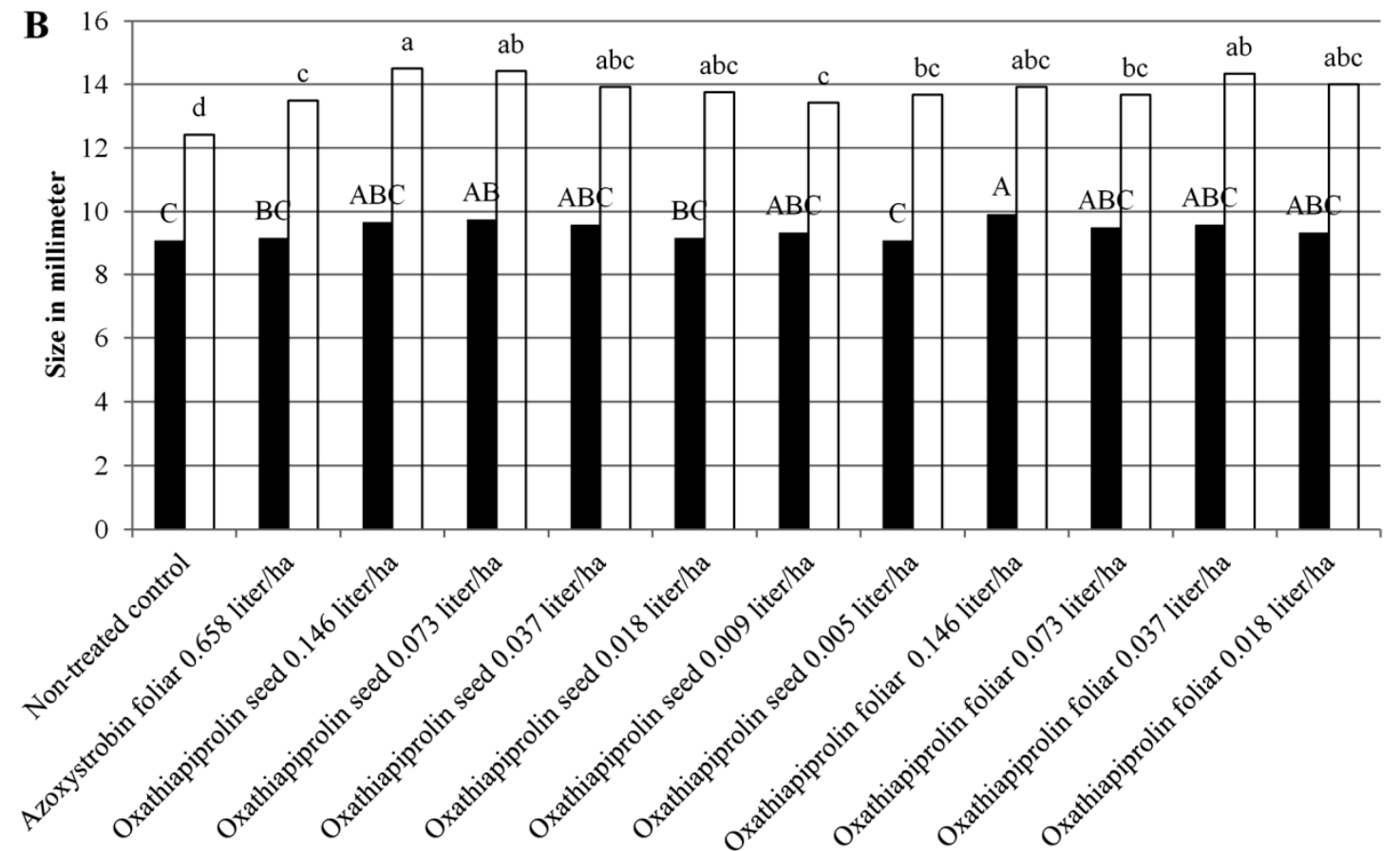

Treatments

FIGURE 1

Average length and width of basil cotyledons at 28 days after planting (DAP) in (A) experiment 1, and 33 DAP in (B) experiment 2. Same letters outside of solid and open bars indicate no significant differences $(P=0.05)$ among the treatments for length and width, respectively. 
downy mildew found with foliar applications of oxathiapiprolin coincided with greater yield in corresponding treatments in field experiment 1 . Similarly, in field experiment 2 , foliar applications of oxathiapiprolin alone, of a tank mix, or in alternation with azoxystrobin or potassium phosphite reduced downy mildew of basil and increased the basil yield compared to the non-treated control (Table 4).

\section{EFFECT OF OXATHIAPIPROLIN ON GERMINATION OF P. BELBAHRI/ SPORANGIA}

The highest sporangia germination of $87.67 \%$ and $81.66 \%$ was found in non-amended water agar in germination experiment 1 and 2, respectively. The $\mathrm{EC}_{50}$ value of $P$. belbahrii in experiment 1 was $0.00040 \mu \mathrm{g} / \mathrm{ml}$, and in experiment 2 it was $0.00033 \mu \mathrm{g} / \mathrm{ml}$ oxathiapiprolin. The lower $95 \%$ fiducial limit of $\mathrm{EC}_{50}$ value in experiment 1 was $0.00038 \mu \mathrm{g} / \mathrm{ml}$ and the upper fiducial limit was $0.00045 \mu \mathrm{g} / \mathrm{ml}$. In experiment 2, the lower fiducial limit of $\mathrm{EC}_{50}$ value was $0.00030 \mu \mathrm{g} / \mathrm{ml}$ and the upper fiducial limit was 0.00035 $\mu \mathrm{g} / \mathrm{ml}$.

\section{IMPLICATIONS FOR BASIL DOWNY MILDEW MANAGEMENT}

Since 2007, numerous fungicide efficacy trials were conducted for control of downy mildew of basil in the United States. Many of these trials tested the same compounds, fungicides, or biological agents with variable efficacy in control of downy mildew of basil in the greenhouse and fields. However, none of these studies evaluated the compounds as seed treatments for their efficacy to manage basil downy mildew. In present study, we evaluated a novel chemical, oxathiapiprolin, as a seed treatment and as foliar applications for its efficacy to manage downy mildew of basil both in the greenhouse and in the field.

The results indicate that seed treatment with oxathiapiprolin provided complete control of downy mildew until 21 and 26 DAP in greenhouse experiments 1 and 2, respectively. This suggests that oxathiapiprolin either systemically moves to foliage from treated seeds or induces defense mechanisms in plants to protect basil from infection with downy mildew pathogen. However, seed treatment with oxathiapiprolin did not reduce downy mildew on basil in field experiments as much as it did in the greenhouse experiments. Reduced suppression of the disease by oxathiapiprolin as a seed treatment in the field trials may be due to prolonged times between the seed treatment (planting) with oxathiapiprolin and the attacks of the pathogen on basil plants. The reduction of disease severity in greenhouse experiment 1 was evaluated under pressure of pathogen attack starting from basil seeding. Therefore, our results suggest that basil seed-treated with oxathiapiprolin should be protected 21 DAP by foliar applications of registered fungicides in South Florida. In the field experiment 1 , symptoms of downy mildew appeared on non-treated control basil 47 DAP, whereas the first disease symptoms appeared 14 DAP and 25 DAP in the greenhouse experiment 1 and 2, respectively. Although basil that had received a seed treatment with oxathiapiprolin in the greenhouse experiment 2 showed significantly lower disease severity at earlier stages after inoculation compared to the non-treated control, the disease rapidly increased over time. This suggests that seed treatment alone will not last long enough for effective control of downy mildew in basil. Further applications of oxathiapiprolin or fungicides as foliar sprays may be needed to protect basil plants against downy mildew for a sufficiently longer period of time.

In dicot plants such as basil, cotyledons are the first part of plants to emerge from the soil. Cotyledons contain the stored food reserves from the seed, providing nutrition for its initial growth.
In addition, photosynthetic activity occurs in cotyledons to promote growth of seedlings (Marshall and Kozlowski 1976). In this study, oxathiapiprolin treatment of basil seedlings significantly increased the width of the cotyledons, which may be beneficial for the growth of basil plants. Hanley and May (2006) reported that damage to cotyledons had a significant adverse effect on growth during the establishment phase of six of the nine plant species. This indicates importance of cotyledons for further growth of seedlings and beyond.

Recently, Ji et al (2014) reported that applications of oxathiapiprolin significantly controlled black shank of tobacco caused by Phytophthora nicotianae compared to the non-treated control under field conditions. In our studies, applications of oxathiapiprolin significantly controlled downy mildew of basil compared to the non-treated control both in greenhouse and field trials. Many studies have indicated that tank mixes of fungicides and applications of fungicides in alternation significantly improved the control of plant diseases, and also played an important role in reducing risk of resistance development in the pathogens (Raid 2011; Wedge et al. 2007; Keinath and DuBose 2004; Culbreath et al. 1995). In this study, oxathiapiprolin applied in a tank mix or in alternation with azoxystrobin and potassium phosphite showed improved efficacy, equivalent to oxathiapiprolin alone, of controlling basil downy mildew. This would be beneficial in maintaining a long period of high efficacy of oxathiapiprolin once it is registered for use on basil for control of downy mildew.

Seed contamination with $P$. belbahrii is considered to be a primary source of inoculum (Belbahrii et al. 2005; Garibaldi et al. 2004b), whereas sporangia serve as the secondary source of inoculum in basil production. The spread of sporangia onto foliage of basil plants and germination rates are critical for infection and for disease development. Results from this study indicated that oxathiapiprolin at low concentrations is effective against $P$. belbahrii in inhibiting sporangia germination and therefore in reducing disease severity and slowing down disease development on basil under greenhouse and field conditions.

Oxathiapiprolin is a new compound active against oomycetes, and currently it is not registered to apply on any crop. In addition, oxathiapiprolin is the first chemical in its chemical group to be developed as a fungicide. To the best of our knowledge, there is no sensitivity test conducted on $P$. belbahrii to oxathiapiprolin. This is the first report of the sensitivity of $P$. belbahrii to oxathiapiprolin. It has been proposed that oxathiapiprolin targets a new single site at oxysterol binding protein (OSBP) to inhibit growth of downy mildew and Phytophthora pathogens (Thomas Fuesler, Dupont, personal communication), so it has potential to develop fungicide resistance in the pathogen. Therefore, fungicide resistance management is important and required for long-lasting effectiveness of this new chemical once it is registered for control of downy mildew. Results from our studies indicate that oxathiapiprolin at 0.018 liter/ha is effective in controlling basil downy mildew in the greenhouse and the field, and the $\mathrm{EC}_{50}$ values from this study can be considered as a reference for future monitoring of changes in sensitivity of $P$. belbahrii to oxathiapiprolin.

In summary, foliar applications of oxathiapiprolin were more effective in reducing basil downy mildew than seed treatment in the greenhouse and field. Results from this study indicate that oxathiapiprolin can be applied as foliar sprays in tank mix or in alternation with azoxystrobin and potassium phosphite in order to reduce the risk of development of potential resistance to this new chemical in $P$. belbahrii. 


\section{ACKNOWLEDGMENTS}

The authors thank Dupont Co. and Syngenta Crop Protection for providing oxathiapiprolin in this study. This research was supported by the United States Department of Agriculture Specialty Crop Research Initiative program (project number 2011-51181-30646).

\section{LITERATURE CITED}

Belbahri, L., Calmin, G., Pawlowski, J., and Lefort, F. 2005. Phylogenetic analysis and Real Time PCR detection of a presumably undescribed Peronospora species on sweet basil and sage. Mycol. Res. 109:12761287.

Culbreath, A. K., Brenneman, T. B., Reynolds, K. L., Hammond, J. M., and Padgett, G. B. 1995. Tank mix combinations of propiconazole and chlorothalonil for control of leaf spot diseases of peanut. Peanut Sci. 22:101-105.

Gang, D. R., Wang, J., Dudareva, N., Nam, K. H., Simon, J. E., Lewinsohn, E., and Pichersky, E. 2001. An Investigation of the storage and biosynthesis of phenylpropenes in sweet basil. Plant Physiol. 125:539555.

Garibaldi, A., Minuto, A., Minuto, G., and Gullino, M. L. 2004a. First report of downy mildew on basil (Ocimum basilicum) in Italy. Plant Dis. 88:312.

Garibaldi, A., Minuto, G., Bertetti, D., and Gullino, M. L. 2004b. Seed transmission of Peronospora sp. of basil. J. Plant Dis. Protect. 111:465469.

Garibaldi, A., Minuto, A., and Gullino, M. L. 2005. First report of downy mildew caused by Peronospora sp. on basil (Ocimum basilicum) in France. Plant Dis. 89:683.

Hanley, M. E., and May, O. C. 2006. Cotyledon damage at the seedling stage affects growth and flowering potential in mature plants. New Phytol. $169: 243-250$

Ji, P., Csinos, A., Hickman, L. L., and Hargett, U. 2014. Efficacy and application methods of oxathiapiprolin for management of black shank on tobacco. Plant Dis. 98:1551-1554.

Keinath, A. P., and Dubose, V. B. 2004. Evaluation of fungicides for prevention and management of powdery mildew on watermelon. Crop Prot. 23:35-42.

Khateri, H., Calmin, G., Moarrefzadeh, N., Belbahri, L., and Lefort, F. 2007. First report of downy mildew caused by Peronospora sp. on basil in Northern Iran. J. Plant Pathol. 89:S70.

Marshal, P. E., and Kozlowski, T. T. 1976. Importance of photosynthetic cotyledons for early growth of woody angiosperms. Physiol. Plant. 37:336-340.
Mcleod, A., Coertze, S., and Mostert, L. 2006. First report of a Peronospora species on sweet basil in South Africa. Plant Dis. 90:1115.

Patel, J. S., Costa de Novaes, M. I., Barbier, M., and Zhang, S. 2013. Evaluation of biopesticides for managing downy mildew of basil. Plant Dis. Manag. Rep. 7:V147. doi:10.1094/PDMR07

Raid, R. N. 2011. Evaluation of various fungicides alternated with a phosphite for control of lettuce downy mildew, spring 2011. Plant Dis. Manage. Rep. 5:V139. doi:10.1094/PDMR05.

Roberts, P. D., Raid, R. N., Harmon, P. F., Jordan, S. A., and Palmateer, A. J. 2009. First report of downy mildew caused by a Peronospora sp. on basil in Florida and the United States. Plant Dis. 93:199.

Ronco, L., Rollán, C., Choi, Y. J., and Shin, H. D. 2009. Downy mildew of sweet basil (Ocimum basilicum) caused by Peronospora sp. in Argentina. Plant Pathol. 58:395.

Shaner, G., and Finney, R. E. 1977. The effect of nitrogen fertilization on the expression of slow-mildewing resistance in Knox wheat. Phytopathology 67:1051-1056

Shepherd, C. P., Bruhn, J. A., Carski, T. H., Summers, B., Hoffman, L. E. Perotin, B., and Sweigard, J. A. 2013. DupontTM ZorvecTM (DPXQGU42, oxathiapiprolin): The first member of a novel class of oomycete fungicides. 4th Int. Phytophthora capsici Conf. A. S. Csinos and P. D. Roberts. Univ. of Florida, Duck Key, FL.

Simon, J. E., Quinn, J., and Murray, R. G. 1990. Basil: A source of essential oils. Pages 484-489 in: Advances in New Crops. J. Janick and J. E. Simon, eds. Timber Press, Portland, OR.

Simon, J. E., Morales, M. R., Phippen, W. B., Vieira, R. F., and Hao, Z. 1999. Basil: A source of aroma compounds and a popular culinary and ornamental herb. Pages 499-505 in: Perspectives on New Crops and New Uses. J. Janick, ed. ASHS Press, Alexandria, VA.

Vieira, R. F., Grayer, R. J., Paton, A., and Simon, J. E. 2001. Genetic diversity of Ocimum gratissimum L. based on volatile oil constituents, flavonoids and RAPD markers. Biochem. Syst. Ecol. 29:287-304.

Vieira, R. F., and Simon, J. E. 2000. Chemical characterization of basil (Ocimum spp.) found in the markets and used in traditional medicine in Brazil. J. Econ. Bot. 54:207-216.

Wedge, D. E., Smith, B. J., Quebedeaux, J. P., and Constantin, R. J. 2007 Fungicide management strategies for control of strawberry fruit rot diseases in Louisiana and Mississippi. Crop Prot. 26:1449-1458.

Wyenandt, C. A., Simon, J. E., McGrath, M. T., and Ward, D. L. 2010. Susceptibility of basil cultivars and breeding lines to downy mildew (Peronospora belbahrii). HortScience 45:1416-1419.

Wyenandt, C. A., Simon, J. E., Pyne, R. M., Homa, K., McGrath, M. T., Zhang, S., Raid, R. N., Ma, L.-J., Wick, R., Guo, L., and Madeiras, A. 2015. Basil downy mildew (Peronospora belbahrii): Discoveries and challenges relative to its control. Phytopathology 105:885-894. 